\title{
Laryngopharyngeal Reflux: Prospective Study Analyzing Various Nonsurgical Treatment Modalities for LPR
}

\author{
Owais Mattoo, Rahil Muzaffar, Anees Mir, Aamir Yousuf, Aakib Hamid Charag, Rauf Ahmad
}

\begin{abstract}
Objective: To compare the outcomes of various medical treatment modalities for laryngopharyngeal reflux (LPR).
\end{abstract}

Study design: Prospective study design.

Materials and methods: $O$ ne-hundred and fifty patients were divided into three groups $(A, B, C)$ based on the mode of intervention used for the control of LPR. Each study group enrolled 50 patients using random tables.

- Group A: These patients were put on a twice daily dosage of esomeprazole ( $20 \mathrm{mg} \mathrm{bd}$ ) and domeperidone (10 mg bd) for 4 months

- Group B: These patients were put on bd dosage of esomeprazole ( $20 \mathrm{mg}$ ) and domeperidone (10 mg) and also received counseling for dietary and lifestyle changes. The duration of treatment was for 4 months.

- Group C: These patients received, in addition to above, $10 \mathrm{mg}$ of amitriptyline (tricyclic antidepressant) bid, again for 4 months.

Results: The success achieved in controlling LPR was defined as greater than $50 \%$ improvement in baseline symptoms. The success achieved in group A was $46 \%$, in group B was $54 \%$ and in group C was $40 \%$.

The relative change in reflux symptom index (RSI) over any given period of time was significantly higher than the relative change in reflux finding score (RFS). The relative change in RSI over first month was $30.99 \%$, which is significantly higher than the relative change of RFS $(6.39 \%)$ over the same period.

The mean RSI scores during 4 months of treatment fell from 20.67 to $8.9(p<0.01)$ in group $A$, from 23.3 to $8.6(p<0.01)$ and from 21.3 to $10.8(p<0.05)$ in group $C$.

The mean RFS during 4 months fell from 15 to $6.5(p<0.05)$ in group $A$, from 16 to $6.4(p<0.05)$ and from 15 to $6.4(p<$ 0.05) in group $C$.

\section{Conclusion}

- All the three interventions had a statistically significant impact on the signs and symptoms of LPR.

- However, higher success rates were achieved in group B where patients were put on a bid dosage esomeprazole and domeperidone nad counseled for lifestyle and dietary changes. Paradoxically, success rates achieved in group $C$ was lower than other groups, possibly because of the anticholinergic effects of amitriptyline causing dry mouth and dry throat.

- The symptomatic improvement was seen much earlier than the improvement in laryngoscopic findings. This was evidenced by the fact that relative change in RSI was much higher than the relative change of RFS over a given period of time.

- If diagnosed with enough surety and certainty, patients of LPR do not need any antidepressant medications as these medications may not have any role in the treatment of same and may, however, worsen the condition owing to their anticholinergic side effects.
Keywords: Laryngopharyngeal reflux, Esomeprazole, Domeperidone, Amitriptyline, Reflux symptom index.

How to cite this article: Mattoo O, Muzaffar R, Mir A, Y ousuf A Charag AH, Ahmad R. Laryngopharyngeal Reflux: Prospective Study Analyzing Various Nonsurgical Treatment Modalities for LPR . Int J Phonosurg Laryngol 2012;2(1):5-8.

\section{Source of support: Nil}

\section{Conflict of interest: None}

\section{INTRODUCTION}

In 1934, B ray suggested a link between gut symptoms and airway disease. Chery reported acid-related laryngeal ulcerations and granulomas in $1968 .{ }^{1}$ Subsequent studies suggested that acid reflux might be a contributory factor in other laryngeal and respiratory conditions. In 1979, Pellegrini and DeM eester were the first to document the link between these airway symptoms and reflux of gastric contents. They also proved that treatment of reflux disease results in elimination of these airway symptoms. ${ }^{2}$ Laryngopharyngeal reflux (LPR) causes a variety of symptoms, including hoarseness, postnasal drip, sore throat, difficulty swallowing, wheezing, chronic cough, globus pharyngis and chronic throat-clearing. Some people with LPR have heartburn, while others have little or none of this symptom. This is because the material that refluxes does not stay in the esophagus for very long and the acid does not have enough time to irritate the esophagus. ${ }^{3}$ These symptoms are most often preval ent just after waking. Foods which have been fried, overly heavy foods or spicy foods, fatty foods may be the most common triggers. ${ }^{8,9}$ Others include coffee, other caffeinated beverages and citrus fruits. Peppermint, although it is popular for controlling stomach issues, actually makes reflux worse, and so it should be cut out of one's laryngopharngeal reflux diet. Certain bad habits also trigger reflux. Smoking, using smokeless tobacco or liquor can all trigger reflux. B eing overweight can also worsen or cause reflux, since excess weight places undue pressure on the esophagus. A LPR diet should be rich in vegetables and fruits and low in fat. ${ }^{4} W$ hile a heavy meal can be satisfying and comforting, it can also trigger heartburn in many people. It is better to take a heavy meal at lunch and a lighter meal in dinner. Having low fat diet has even greater benefits. One should avoid drinking water, juices, etc. just before going to bed. ${ }^{7}$ Twice daily dosage of 
PPIs has been found to be more effective than OD dosage. ${ }^{11}$ The diagnosis of LPR is often difficult. ${ }^{10}$ The symptom complex of LPR is seen in a no. of medical and surgical conditions of head and neck, ${ }^{10}$ and as a result this condition cannot be diagnosed on symptoms alone. Laryngoscopic findings such as erythema, edema, laryngeal granulomas and interarytenoid hypertrophy have been used to establish the diagnosis; but these findings are very nonspecific, and have been described in the majority of asymptomatic subjects undergoing laryngoscopy. ${ }^{5}$ A diagnosis can be made with a thorough medical history, general examination with emphasis on gastroenterological examination and chest examination, complete head and neck examination. In our study, a diagnostic criteria was established to diagnose L PR. The findings suggestive of L PR include posterior laryngitis, pseudosulcus vocalis, ventricular effacement, mucosal hypertrophy, laryngeal pachydermia (granularity, cobblestone), ulcers, granulomas, scarring and stenosis. ${ }^{5}$

\section{MATERIALS AND METHODS}

A prospective study was conducted on 150 individuals diagnosed as patients of $L P R$, who attended the 'D epartment of ORL and Head and Neck Surgery' of Government Medical College Srinagar and Associated Hospitals' over 12 months period from September 2010 to September 2011. The patients included in the study were all adults between age group 30 and 50 years (mean age group, 42.3 years). We excluded from our study patients with other comorbid conditions like stoke, cardiovascular diseases, or other severly impaired or handicapped individuals. This was done to avoid loss of patients to follow-up. We also excluded patients who had associated disorders like cholecystitis, pancreatitis, irritable bowel syndrome, moderate-to-severe anemia, jaundice and patients with diabetes. A II the patients included in study presented with one or more of the symptoms consistent with LPR. Relevant patient details, comorbid conditions and medications were recorded on a study proforma.

A diagnosis was made with a thorough medical history, general examination with emphasis on gastroenterological examination and chest examination: Complete head and neck examination. In our study, a reflux symptom index (RSI) and reflux finding score (RFS) were used to establish the diagnosis of $L P R$, and also to compare the results pre and posttreatment. Scores $>13 \mathrm{RSI}$ and $>7$ RFS were used to establish the diagnosis of $L P R$, and accordingly only such patients were included in the study.

\section{Reflux Symptom Index}

$\begin{array}{ll}\text { Within the last month, } & 0=\text { No problem } \\ \text { how did the following } & 5=\text { Severe problem }\end{array}$

problems affect you?

\begin{tabular}{|c|c|c|c|c|c|c|c|}
\hline & $\begin{array}{l}\text { Hoarseness or a problem } \\
\text { with your voice }\end{array}$ & 0 & 1 & 2 & 3 & 4 & 5 \\
\hline 2. & Clearing your throat & 0 & 1 & 2 & 3 & 4 & 5 \\
\hline 3. & $\begin{array}{l}\text { Excess throat mucus or } \\
\text { postnasal drip }\end{array}$ & 0 & 1 & 2 & 3 & 4 & 5 \\
\hline 4. & $\begin{array}{l}\text { Difficulty swallowing food, } \\
\text { liquids or pills }\end{array}$ & 0 & 1 & 2 & 3 & 4 & 5 \\
\hline 5. & $\begin{array}{l}\text { Coughing after you eat or } \\
\text { lying down }\end{array}$ & 0 & 1 & 2 & 3 & 4 & 5 \\
\hline & $\begin{array}{l}\text { Breathing difficulties or } \\
\text { choking episodes }\end{array}$ & 0 & 1 & 2 & 3 & 4 & 5 \\
\hline 7. & $\begin{array}{l}\text { Troublesome or } \\
\text { annoying cough }\end{array}$ & 0 & 1 & 2 & 3 & 4 & 5 \\
\hline 8. & $\begin{array}{l}\text { Sensations of something } \\
\text { sticking in your throat or a } \\
\text { lump in your throat }\end{array}$ & 0 & 1 & 2 & 3 & 4 & 5 \\
\hline 9. & $\begin{array}{l}\text { Heartburn, chest pain, } \\
\text { indigestion or stomach } \\
\text { acid coming up }\end{array}$ & 0 & 1 & 2 & 3 & 4 & 5 \\
\hline
\end{tabular}

Scores $>13$ were taken as suggestive of LPR

\section{Reflux Finding Score}

- Infraglottic edema (pseudosulcus vocalis)

0 (absent), 2 (present)

- Ventricular obliteration

0 (none), 2 (partial),

4 (complete)

- $\quad$ Erythema/hyperemia

0 (none), 2 (arytenoids), 4 (diffuse)

- Vocal fold edema

0 (none), 1 (mild), 2 (moderate), 3 (severe), 4 (polypoid)

- Diffuse laryngeal edema

0 (none), 1 (mild), 2 (moderate), 3 (severe), 4 (obstruct)

- Posterior commissure hypertrophy

0 (none), 1 (mild), 2 (moderate), 3 (severe), 4 (obstruct)

- Granuloma or granulation

0 (absent), 2 (present)

- Thick endolaryngeal mucus

0 (absent), 2 (present)

Scores $>7$ were taken as suggestive for LPR

Only those patients were included in this study who had a RSI >13 and RFS >7. This was done to establish the diagnosis of LPR with a high degree of surety and certainty. Supplemented with this was the fact that other conditions mimicking LPR were ruled out. Postnasal drip, allergy, Zenker's diverticulum, sensory neuropathy or excessive sensitivity of throat can all lead to chronic throat clearing, mimicking LPR. Patients were put on a regular follow-up and at each follow-up, these scores were calculated: ${ }^{8}$

- B efore starting treatment

- At 1 month 
Laryngopharyngeal Reflux: Prospective Study Analyzing Various Nonsurgical Treatment Modalities for LPR

- At 2 months

- At 4 months ${ }^{11}$

PPIs do alter the $\mathrm{pH}$ of gastric juices and provide relief from most of the symptoms of gastroesophageal reflux disease (GERD) but reflux may still persist. I thas been seen that total gastric reflux may remain same but the $\mathrm{pH}$ of the gastric juices refluxing is altered. ${ }^{6}$ Compared with omeprazole, its S-isomer (esomeprazole) displays lower first-pass hepatic metabolism and slower plasma clearance; this results in higher plasma concentration and highly effective inhibition of gastric acid secretion. Esomeprazole, the S-isomer of omeprazole, has been shown to have higher healing rates of erosive esophagitis than omeprazole. As such, esomeprazole was used in our study for the suppression of gastric $\mathrm{pH}$. Esomeprazole $20 \mathrm{mg}$ bid was used in all of these patients as bid dosage has been shown to be more effective than OD dosage. The use of domeperidone has again been controversial, some supporting its use while some finding its use statistically insignificant in our study, domeperidone $10 \mathrm{mg}$ bd was used in patients of LPR.

Dietary modifications included avoiding alcohol and caffeine. Fatty meal, fried foods, spicy meals, chocolates were also advised to be avoided. Patients were advised to go to bed after 3 hours of having dinner. The head end of the bed was elevated by keeping two bricks under the legs of the head end side of the bed. This provided a sufficient elevation of $30^{\circ}$. Patients were also advised not to take any water, milk and juices, etc. just before going to bed.

Additionally in another group, antidepressant amitriptyline was used in a dosage of $10 \mathrm{mg}$ bid.

- Group A: These patients were put on bid dosage of esomeprazole $20 \mathrm{mg}$ and domeperidone $10 \mathrm{mg}$.

- GroupB: In addition to esomeprazole and domeperidone (bid), these patients were counseled about the dietary and lifestyle modifications.

- Group C: These patients were put on a combination of esomeprazole and domeperidone: A mitriptyline $10 \mathrm{mg}$ bid: and dietary and lifestyle modifications.

Patients who had symptomatic improvement and whose scores of RSI posttreatment were $<10$ and RFS $<5$ were taken as to have a significant improvement in symptoms ${ }^{12}$ at 4 months.

\section{RESULTS, ANALYSIS AND STATISTICS}

This study analyzed a group of 100 patients, divided into three groups. Each group was subjected to a particular treatment modality. In group A, patients were put on a bid dosage of esomeprazole and domeperidone. Twenty three
$(46 \%)$ patients reported significant improvement in their symptoms ( $50 \%$ improvement in their symptoms from the baseline). A nother 10(5\% patients) reported some improvement and rest (44\%) achieved no improvement at all.

Likewise in group B , 27 patients (54\%) reported greater than $50 \%$ improvement in their symptoms; 4 patients (8\%) had some improvement and rest 38\% (19 patients) had no improvement at all.

In group C, paradoxically only 20 patients (40\%) achieved significant improvement from their baseline symptoms. A nother $8 \%$ (4 patients) reported some improvement whereas $52 \%$ (26 patients) achieved no improvement at all.

\begin{tabular}{cccc}
\hline Groups & $\begin{array}{c}\text { Significant } \\
\text { improvement }\end{array}$ & $\begin{array}{c}\text { Some } \\
\text { improvement }\end{array}$ & $\begin{array}{c}\text { No } \\
\text { improvement }\end{array}$ \\
\hline A & $46 \%$ & $10 \%$ & $44 \%$ \\
B & $54 \%$ & $8 \%$ & $38 \%$ \\
C & $40 \%$ & $8 \%$ & $52 \%$ \\
\hline
\end{tabular}

As expected, the RSI scores began to fall earlier than RFS. During a strict follow-up, patients reported an improvement in their symptoms but the laryngoscopic examination could not detect any change from the baseline. Following table summarizes the scores of RSI and RFS at monthly intervals.

\begin{tabular}{ccccc}
\hline 0 & 1 & 2 & 3 & 4 \\
month & month & months & months & $\begin{array}{c}4 \\
\text { months }\end{array}$ \\
\hline
\end{tabular}

$\begin{array}{llllll}\text { RSI } & 22.68 \pm 1.78 & 15.65 \pm 1.33 & 10.87 \pm 1.09 & 9.00 \pm 0.66 & 8.33 \pm 1.23\end{array}$ RFS $\quad 13.76 \pm 0.89 \quad 12.88 \pm 0.98 \quad 9.76 \pm 1.66 \quad 6.68 \pm 1.22 \quad 5.86 \pm 1.00$

Mean scores for 150 patients

The scores of RSI and RFS for individual groups as observed in this study is tabulated and observed p-value calculated to show the significance of the treatment modality on symptoms and signs of $\mathrm{LPR} .^{9}$

\begin{tabular}{|c|c|c|c|c|}
\hline Group A & $\begin{array}{l}\text { Pretreatment } \\
\text { score }\end{array}$ & $\begin{array}{l}\text { Score after } \\
4 \text { months of } \\
\text { treatment }\end{array}$ & $\chi^{2}=(0-e)^{2} / e$ & $p$-value \\
\hline RSI & 20.67 & 8.9 & 6.70 & $<0.01$ \\
\hline RFS & 15.00 & 6.5 & 4.81 & $<0.05$ \\
\hline Group B & $\begin{array}{l}\text { P retreatment } \\
\text { scores }\end{array}$ & $\begin{array}{l}\text { Score after } \\
4 \text { months of } \\
\text { treatment }\end{array}$ & $\chi^{2}=(0-e)^{2} / e$ & $p$-value \\
\hline RSI & 23.3 & 8.6 & 9.27 & $<0.01$ \\
\hline RFS & 16.0 & 6.4 & 5.76 & $<0.05$ \\
\hline Group C & $\begin{array}{l}\text { P retreatment } \\
\text { scores }\end{array}$ & $\begin{array}{l}\text { Score after } \\
4 \text { months of } \\
\text { treatment }\end{array}$ & $\chi^{2}=(0-e)^{2} / e$ & $p$-value \\
\hline RSI & 21.3 & 10.8 & 5.176 & $<0.05$ \\
\hline RFS & 15.0 & 6.40 & 4.93 & $<0.05$ \\
\hline
\end{tabular}




\section{DISCUSSION}

The treatment of LPR has been a matter of debate for decades. Studies have been conducted with various PPIs and the role of each has been debated and counter debated. As the difficulty in diagnosing this condition prevails, some authors have supported the use of antidepressant medication in these conditions. A stonishingly, no study has been done so far to analyze the use of antidepressant medication in extraesophageal reflux. This study evaluated patients' symptoms and signs, and the impact of the drugs (PPIs and prokinetic drugs), lifestyle changes and antidepressant medication amitriptyline on LPR. This study concluded that all the three modalities have a statistically significant impact on signs and symptoms of LPR. Higher success rate was achieved in the group B. Thus, lifestyle modifications including keeping a wide time gap between meals and sleep, elevating the head end of the table: Dietary modifications like cessation of smoking, alcohol, avoiding fatty foods, spicy foods, have a significant impact on the treatment of LPR. Paradoxically, the success achieved in the group $C$ was lower than groups $A$ and $B$, though, significant improvement was seen with this intervention as well. As is known, amitriptyline has anticholinergic side effects leading to dry mouth and dry throat. These side effects may mimic the symptoms of LPR and thus may be the reason of lower success rate achieved. Other side effects on account of its anticholinergic activity are drowsiness, weight gain, changes in appetite, muscle stiffness, nausea, constipation, nervousness, dizziness, blurred vision, urinary retention, insomnia and changes in sexual function. Thus, all patients diagnosed with LPR should be put on bid dosage of esomeprazole and domeperidone: At the same time counseled for lifestyle and dietary modifications. If diagnosed with certain degree of surety, as is achieved by using RSI and RFS scores, patients of LPR need no antidepressant medications. These medications may, in fact, aggravate the symptoms of LPR. Patients of LPR on treatment showed improvement in their baseline symptoms much earlier than the laryngoscopic change in the signs. This was evidenced from the fact that the relative change in RSI over any given period of time was significantly higher than the relative change in RFS. The relative change in $\mathrm{RSI}$ over first month was $30.99 \%$, which is significantly higher than the relative change of RFS $(6.39 \%)$ over the same period.

\section{REFERENCES}

1. Cherry J, M argulies SI. Contact ulcer of the Iarynx. L aryngoscope 1968 Nov;78(11):1937-40.

2. Pellegrino CA, DeM eester TR, Johnson LF, Skinner DB. Gastroesophageal reflux and pulmonary aspiration: Incidence, functional abnormality, and results of surgical therapy. Surgery 1979 J ul;86(1):110-19.

3. Laryngopharyngeal Reflux (Silent Reflux): The Basics. jamiekoufman.com. 2010 [last update].

4. www.heartburn-stop.com/laryngopharyngeal-reflux-diet/.

5. Hicks DM, O urs TM, A belson TI, V aezi M F, Richter JE. The prevalence of hypopharynx findings associated with gastroesophageal reflux in normal volunteers. J Voice 2002 Dec;16(4):564-79.

6. Tamhankar AP, Peters JH, Portale G, et al. Omeprazole does not reduce gastroesophageal reflux: $\mathrm{New}$ insights using multichannel intraluminal impedance technology. J Gastrointest Surg 2004 Nov;8(7):890-97; discussion 897-98.

7. Hunchaisri N. jmat.mat.or.th. T reatment of laryngopharyngeal reflux: A comparison between domperidone plus omeprazole and omeprazole alone. J M ed A ssoc Thai 2012;95(1):73-80.

8. V Pham utmb.edu. The L aryngopharyngeal Reflux 2009.

9. Renato J Giacchi, Daniel Sullivan, Stephen G Rothstein. Compliance with antireflux therapy in patients with otolaryngologic manifestations of gastroesophageal reflux disease. The L aryngoscope 2000 J an;110(1):19-22.

10. B elafsky PC, Postma GN, A min M R, K oufman J A. Symptoms and findings of laryngopharyngeal reflux. Ear Nose Throat J 2002 Sep;81(9 Suppl 2):10-13.

11. W oosuk Park, Douglas M Hicks, Farah Khandwala, J oel E Richter, Tom I Abelson, ClaudioM ilstein, M ichael F V aezi. L aryngopharyngeal reflux: Prospective cohort study evaluating optimal dose of proton-pump inhibitor therapy and pretherapy predictors of response. The Laryngoscope $2005 \mathrm{~J}$ uly; 110(7):1230-38.

12. Gregory N Postma, Stacey L Halum. Laryngeal and pharyngeal complications of gastroesophageal reflux disease. GI M otility online 2006.doi: 10.1038/gimo46.

\section{ABOUT THE AUTHORS}

\section{Owais Mattoo (Corresponding Author)}

Postgraduate, Department of ENT and HNS, Government M edical College Srinagar, J ammu and K ashmir, India, e-mail: owais.mattoo@ rediffmail.com

\section{Rahil Muzaffar}

Postgraduate, Department of ENT and HNS, Government M edical College, Jammu and Kashmir, India

\section{Anees Mir}

Department of ENT and HNS, Government M edical College Jammu and Kashmir, India

\section{Aamir Yousuf}

Postgraduate, Department of ENT and HNS Government M edical College, Jammu and Kashmir, India

\section{Aakib Hamid Charag}

Postgraduate, Department of General Surgery, Sher-i-K ashmir Institute of M edical Sciences, Jammu and Kashmir, India

\section{Rauf Ahmad}

Associate Professor, Department of ENT and HNS, Government M edical College, Jammu and K ashmir, India 